\title{
Ethical Perspective of Health Sector Reform Process in Nepal
}

\author{
- Sapkota VP1 \\ ${ }^{1} \mathrm{MPH}$ Candidate, University of Southern Denmark, Denmark
}

\section{Introduction}

Reform in health system is an ongoing process in all countries. It aims to achieve sustained, purposeful and fundamental change in the health sector. (1) The initiatives to bring about reform are social experiments that try to systematically transform the health system to the stage where they are more equitable, efficient and accountable. In developing countries such social experiments started in 1980s as a way of providing new resources to the underfunded public system which were often initiated by external agentsthe World Bank (WB) and International Monitory Fund (IMF). (2) Such reforms created huge problems on equity, health service delivery and sustainability in most of the African nations. (2, 3) Therefore, in many circumstances reforms may not only fail to accomplish the avowed goals, but their long lasting effects can make it more difficult to implement better reforms. (2)

The gravity of importance realized with the reform experiments, the public health expert and policy makers agreed upon the fact that reform process must undergo a through ethical and scientific review so that the outcome in the health system won't stray away from those anticipated. The ethical review in public health sorts into three major categories: utilitarianism, which focuses on consequenceswhere people end up; liberal focuses on rights and opportunities-where people start; and communitarianism focuses on kinds of individuals and communities that are sought to create. (4) The nation should consider the ethical proposition- egalitarian liberal: everyone has a positive right to minimum level of services and resources needed to assure fair equality of opportunity-while considering the policy decisions of reforming the health sector. (2) This positive right perspective makes the government responsible for a minimum quantity and quality of life for all, and provides health care needed to guarantee that minimum. (4) The positive right argument generally leads to a re-distributive perspective that favors those people who are worst off from a lifetime perspective. (2) The benchmarks for fairness developed by Denial et. al operationalize this ethical position into an integrated view of how we seek equity (Inter sectoral Public Health; financial and non-financial barriers to access; financing health services), Efficiency (efficacy, efficiency and quality improvement; Administrative efficiency) and
Accountability (democratic accountability and empowerment and patient and provider autonomy) in the health policy reform initiative. (5) The fairness of health sector reform will be judged against the aforementioned benchmark sets.

Health service delivery and reform process in Nepal

Nepal, a small country, lies in central Himalayas, is wedged between India and China. Ministry of Health and Population (MoHP) is the apex body responsible for delivery of health services. National Health Policy-1991 is the fundamental policy that is strongly based on Primary Health Care and determines the health care delivery mechanisms of the country. The constitution of Nepal has enshrined health of Nepalese people as basic human right and hence the country is committed to deliver Essential Health Care Services (EHCS) free of cost to its entire population. The EHCS is basic package of highly cost effective public health interventions that includes the services that are the most cost-effectivethat have the biggest potential impact in reducing mortality per rupee spent. (6) The EHCS is the integral part of Primary Health Care in Nepal. These interventions are strongly population focus. The provision of EHCS is extended up to the community level-the lowest unit of public health service delivery in Nepal. The Department of Health Services is responsible for delivery of EHCS at all levels of service delivery. $(6,7)$

Health sector reform process started in Nepal since 2002 with the formulation of Nepal Health Sector programme: An Agenda for Reform (2002-2015), a long term sector reform strategy. First phase of long term reform strategy developed as Nepal Health Sector Programme-Implementation Plan (NHSP-IP) (2004-2009) has been implemented successfully. And, now the second phase-NHSP-II (2010-2015) is in the process of execution.

The current article tries to look into the reform initiatives from the ethical perspective adopting the ethical position of Egalitarian Liberal, and to analyze the arrangements of reform from the equity-efficiency and accountability perspective.

\section{Perspectives:}

\section{Equity}

"In order to maintain the equity in the distribution of health in its population, the state must distribute, as 
equitably as it can, not only the risk of getting illness but also the means of overcoming it. To distribute the risk of illness and consequently the health equitably, the social determinants of health must be distributed in the just way". (2) For this, health sector has limited role to play but still the notion of inter-sectoral focus of public health limitedly addresses it. More recently, looking health in every public policy increases the horizon of intersectoral public health. NHSP-II has a strong focus on inter-sectoral public health. Hygiene, water and sanitation, food and nutrition, rural infrastructure and housing, education and information are the areas where NHSP-II has delineated the clear roles of Health and counterpart ministry whom it will collaborate with for these activities. (6) But the initiatives to transform Ministry of Health and Population with stewardship role to monitor the health in every public policy are feeble in NHSP-II.

"NHSP-II outlined systematic steps towards monitoring health inequalities over the plan time period. It has planned annual household survey that continues to monitor the anticipated change in the population health characteristics. The plan also anticipates the monitoring of free essential health care strategy to bring about timely changes in the programme to search for more effective ways to reduce the inequalities." (6)

The other aspect of the fair equality of opportunity includes: whether the reform included the ways to gradually improve universal access to basic package of primary health care. (2) The informal (non-taxable) sector is a majority in Nepal and fairness further requires reducing financial and non-financial barriers to access these services. (5) The NHSP-II actions ensure Free Essential Health Care Services up to district level to all the people and gradually increase the services covered under the package of EHCS. (6) For the small formal sector (taxable) living in the urban, "There will be scope for continued growth of private insurance-based options for the urban formal sector population, which will help to reduce the pressure of demand from the better off for services funded from taxation. It will be important to ensure that formal insurance schemes with mainly better-off recipients recover all of their costs and are not implicitly receiving subsidised access to public-sector facilities." (6) This initiative is assumed to gradually decrease the out of pocket expenditure on health.

"NHSP-II addresses non-financial barriers to access the EHCS by the formula based budget allocation in order to address allocative efficiency and equity issues and to reduce the distortion that arises as the result of discretionary allocation of resources. This approach will adjust per-capita allocations to reflect the higher costs of delivering services in Hill and Mountain regions, the disease burden, and the relative poverty of the population." (6) Furthermore, gender has been included in the part of essential Health Care services particularly during the delivery of $\mathrm{RH}$ services; discrimination by race religion, class in offering services in public places is attempted to address with Gender Equality and Social Inclusion (GESI) strategy: removal of cultural and financial barriers for health services. (6)

"The ministry assumes the middle case scenario for financial resource allocation for NHSP-II over the plan duration. It anticipates that there will be a gradual increase in the Government and EDP share of total spending on NHSP-II. Average annual increment in spending is high for EDPs $(9,5 \%)$ as compared to Government share $(7.7 \%)$. Nearly half of public health spending is financed by EDPs." (6) Government should try to increase total share of its budget in-order to gradually develop sustainable fiscal space for the public health services.

\section{Efficiency}

"Sometimes the concept of efficiency may seem to conflict with equity and fair distribution of health as our account here is not equivalent to maximizing health benefits regardless of who gets it(as per the utilitarian principle). A just health requires the efficient functioning of the system that aims to promote the normal functioning of the population fairly. One system can be said more efficient than another if it achieves same fair distribution of health outcome with fewer resources as inputs or if it achieves a fair distribution of a better set of health outcomes with comparable resource inputs." (2)

To operationalize the concept, the designed primary health care system for community based service delivery should get maximum value for it i.e. it should treat the majority of health problems in the community and avoid the unnecessary referrals to the higher centre for basic health care services. (5) The reform initiative should work to make the PHC system as efficient as possible.

"The EHCS is the integral part of Primary Health Care in Nepal. These interventions are strongly population focus. The provision of EHCS is extended up to the community level-the lowest unit of public health service delivery in Nepal. The prime focus of the NHSP-II is to extend and sustain the coverage of EHCS. The task of NHSP-2 is therefore to continue to increase the proportion of the population benefiting from the existing EHCS package of services, with a particular focus on all women receiving reproductive health services and the poor and excluded. The level of service delivery for EHCS is Community, Health facility, District Hospital in order to maintain the appropriate referral." (6) Therefore these primary health care interventions are highly efficient covering majority of the population and their basic health problems with appropriate use of resources.

Promoting evidence based practice-an integral part to 
maintain and gradually improve the efficiency of health care interventions, identifying the new technologies, testing the effectiveness in public health setting according to the public health needs is simply not identified by the reform initiative. Some of it is performed by Nepal Health Research Council (NHRC), but no further activities suggested as how to strategically improve and increase the resource allocation in this regard. Some initiative has been taken in the direction of creation of evidence based data base for health care technology and best practices in health service delivery. But unifying mechanism for the Health service research for policy and programme design is hardly found. NHSP-II didn't outline concrete ways and roles of current research bodies towards systematising current research practice for policy and programme design.

Improving the quality of health services, the NHSP-II basically focused on increasing the training capacity of Ministry of Health and Population by developing National Health Training Center into an autonomous body. (6) The recent reorganisation includes Quality of care as a part of management division. NHSP-II takes into account quality of care as critical to achieving MDGs and hence greatly focuses it in production and deployment of various categories of health workers, continuing training and education, health service trainings and performance based and retention based payment system for existing health workers. (6)

In order to maintain the administrative efficiency, the NHSP-II states, "In the context of expanding coverage of EHCS to more equitably meet the needs of all citizens, particularly the needs of the poor and excluded groups, it is imperative that a well-planned and functional health infrastructure in an enabling environment for delivering quality health services nationwide be in place". The plan has outlined the clear set of reform measures in the areas of health Infrastructure development, efficient management of personnel and appropriate technology acquisition; appropriately decentralizing these initiatives so that the administrative efficiency will be maintained particularly at primary health care level. (6) On the other hand, the plan didn't set out appropriate measures to prevent the brain drain and particularly minimizing abuse and inappropriate incentives at local level. Additional actions to improve administrative efficiency: Governance and Accountability Action Plan (GAAP); Financial Management Improvement Action Plan; introduction of central bidding and local purchasing schemes (2009/2010) to reduce the fiduciary risks and improve availability and quality of drugs and medical supplies at service delivery points. (6) Most of the aspects of administrative efficiency are related to accountability. For example, the decentralization of health services to local community-which the NHSP-II takes at its heart to system management-will improve many of the administrative inefficiencies.

\section{Accountability}

This criterion basically tries to assess if holding institutions in the health sector are accountable to the public; they actually increase the power of the public to act the remedy the problem. (5) The Accountability for reasonableness principle is taken into account to see whether the reform initiative consider the accountability into its agenda of reforms. (5) The NHSPII outlines the following actions in order to bring about accountability and good governance issues in the health system over the 5 years period.

1) Accountability and local ownership: increased ownership to community based programmes.

2) Role of local governance in PHC: local stakeholders are more conscious of their needs. So NHSP-II has action to transfer clear functional assignments with proper financial backup for different levels of health governance.

3) Capacity building of local health management committee (basically local governance for health service delivery has been envisioned by NHSP-II)

4) Voice and accountability: policy issues using different policy forums (for example, Health Sector Decentralisation Policy Forum and others) as platforms to discuss and bring forth various policy issues in the main agenda of policy makers.

5) The plan has identified need for engaging citizens and communities actively and holding the service provider accountable to local people.

As overall, Nepal is undergoing the state restructuring process where federalism and decentralization will be common for all public sectors. Therefore, accountability along with the governance issues will be better addressed.

\section{Discussion and Conclusion}

NHSP-II has very progressive actions to ensure and expand the EHCS to the rural population; enhance the efficiency particularly the administrative efficiency for smooth delivery of EHCS at local level and ensure the good governance and accountability. Still some of the areas the NHSP-II dealt with conflicts with or don't hold the ethical position of Egalitarian liberal for the reform process.

In an attempt to maintain the equity in health, the reform attempt tries to do a lot in maintaining the equitable access to health services particularly for rural population. In this area the reform initiative is really commendable; but focus 
on intersectoral approach is limited. No clear actions are mentioned to devise the mechanism to distribute social determinants of health as equitably as possible which is necessary to ensure the health as human right otherwise only the right to health services will be ensured not right to health. Ministry should be given the stewardship role where it will see the impact of health in every social policy; this will be a strong and proactive step towards working on social determinants of health which is necessary to cope with the changing pattern of diseases i.e. from communicable to noncommunicable diseases and many more challenges.

The NHSP-II has taken initiatives towards creating additional fiscal space to add many of cost effective public health interventions in current EHCS to expand the primary health care services to rural population. These basically include health promotion and mechanism to address neonatal mortality, rising non-communicable diseases and malnutrition. To generate resources for the additional fiscal space, the NHSP-II assumes that there will be progressive increase in the EDP budget available to Ministry of Health and Population. But the assumed average growth in EDP's budget available to MoHP is greater than government's own. This additional fiscal space seems unsustainable and such interventions in long run will do more harm than good. Therefore, no strategic options have been developed to make the health services delivery financially more sustainable; some are proposed but they are fragmented and don't ensure the financial sustainability as just health needs. (6)

A whole, lot of actions are enlisted to make the health services delivery at community level more efficient by adopting the concept of Primary Health Care and improving it gradually. Actions to improve the administrative efficiency are also progressive. But not concrete actions are developed to address the problem of Brain drain. Similarly, capacity improvement in research and development of new technologies for health services is not comprehensive which is mandatory to gradually improving the efficiency of current interventions and develop and test new, efficient and innovative public health interventions. Some actions are proposed but they are very fragmented and as per the donor interest. No clear actions are proposed to systematically improve the research capacity in the areas of health service research.

Actions to bring about reform in accountability of health services delivery both at community and policy planning level are clear. The plan assumes decentralization of health services to the local people as a central strategy to make the services more accountable to the community. Arrangements of policy discussion forums for health services to raise the voice to the policy makers are also ensured. But performance on this component in coming days more depends on country's overall development and reform in general public sector

\section{References:}

1. Berman P. Health sector reform: making health sector sustainable. Health Policy. 1995 Jan 24; 32(1995):13-18.

2. Daniels N. Just Health: Meeting Health Needs Fairly. Cambridge University Press: 2008.

3. Berman P, Bossert TJ. A Decade of Health Sector Reform in Developing Countries: What Have We Learned? DDM Symposium: Appraising a Decade of Health Sector Reform in Developing Countries. Washington, D.C. March 15, 2000.

4. Roberts MJ, Hsiao W. Berman P, Reich MR. Getting the reform right: A Guide to Improve Performance and Equity. Oxford University Press: 2004.

5. Daniels N, Flores W. Pannarunothai S, Ndumbe PN, Bryant JH, Ngulube TJ, Wang Y. An evidence-based approach to benchmarking the fairness of health sector reform in developing countries. Bulletin of World Health Organization 2005; 83:534540 .

6. Government of Nepal, Ministry of Health and Population, Nepal Health Sector Program-II. National Planning Commission, Kathmandu, Nepal. 2011.

7. Government of Nepal, Ministry of Health and population, National Health Policy 1991. Kathmandu, Nepal. 1991. 